Check for updates

Cite this: Sustainable Energy Fuels, 2019, 3, 2337

Received 8th May 2019

Accepted 3rd June 2019

DOI: $10.1039 / \mathrm{c} 9 \mathrm{se} 00289 \mathrm{~h}$

rsc.li/sustainable-energy

\section{Enhanced water splitting through two-step photoexcitation by sunlight using tantalum/ nitrogen-codoped rutile titania as a water oxidation photocatalyst $\uparrow$}

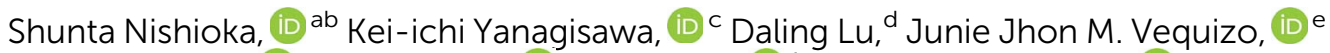
Akira Yamakata, (D) Koji Kimoto, (D) Miki Inada (iD f and Kazuhiko Maeda (DD *a

Rutile $\mathrm{TiO}_{2}$ codoped with tantalum and nitrogen $\left(\mathrm{TiO}_{2}: \mathrm{Ta}, \mathrm{N}\right)$ was assessed as a water oxidation photocatalyst for Z-scheme water splitting driven by visible light. This material was prepared by thermal ammonolysis of $\mathrm{TiO}_{2}$ :Ta with dry $\mathrm{NH}_{3}$ at $773 \mathrm{~K}$, while samples of the oxide precursor were synthesized using a microwave-assisted solvothermal technique, applying various conditions. The photocatalytic activity of the $\mathrm{TiO}_{2}: \mathrm{Ta}, \mathrm{N}$ during water oxidation to $\mathrm{O}_{2}$ from an aqueous $\mathrm{FeCl}_{3}$ solution was found to be greatly affected by the synthesis parameters. The rate of $\mathrm{O}_{2}$ evolution was increased upon increasing the level of $\mathrm{Ta}$ doping in conjunction with a highly-crystalized $\mathrm{TiO}_{2}: \mathrm{Ta}$ precursor resulting from applying a higher temperature during synthesis of the oxide. $\mathrm{IrO}_{2}$ loading of the $\mathrm{TiO}_{2}: \mathrm{Ta}, \mathrm{N}$ photocatalyst also improved the $\mathrm{O}_{2}$ evolution activity. The optimized $\mathrm{IrO}_{2} / \mathrm{TiO}_{2}: \mathrm{Ta}, \mathrm{N}$ photocatalyst was applied to a Zscheme water splitting system in combination with $\mathrm{Ru} / \mathrm{SrTiO}_{3}: \mathrm{Rh}$ and in the presence of redox mediators $\left(\mathrm{Fe}^{3+/ 2+}\right.$ or $\left.\left[\mathrm{Co}(\mathrm{bpy})_{3}\right]^{3+/ 2+}\right)$. Under AM1.5G simulated sunlight, this system exhibited a maximum solar-tohydrogen energy conversion efficiency of $0.039 \%$, which was nearly twice as high as the previously reported system with the use of $\mathrm{RuO}_{2} / \mathrm{TiO}_{2}: \mathrm{Ta}, \mathrm{N}(0.021 \%)$.

\section{Introduction}

The photocatalytic splitting of water into $\mathrm{H}_{2}$ and $\mathrm{O}_{2}$ is one potential means of producing $\mathrm{H}_{2}$ using solar energy. ${ }^{1-6}$ Semiconductors capable of absorbing visible light have been extensively studied over the last half century as photocatalysts for water splitting, because visible light accounts for approximately one half of the energy contained in sunlight. ${ }^{1-6}$ Various reaction schemes have been proposed for water splitting. Among these, the two-step photoexcitation system referred to as the Z-scheme,

${ }^{a}$ Department of Chemistry, School of Science, Tokyo Institute of Technology, 2-12-1-NE-2 Ookayama, Meguro-ku, Tokyo 152-8550, Japan. E-mail: maedak@chem. titech.ac.jp

${ }^{b} J a p a n$ Society for the Promotion of Science, Kojimachi Business Center Building, 5-3-1 Kojimachi, Chiyoda-ku, Tokyo 102-0083, Japan

'Electron Microscopy Group, Research Center for Advanced Measurement and Characterization, National Institute for Materials Science, 1-1 Namiki, Tsukuba, Ibaraki 305-0044, Japan

${ }^{d}$ Suzukakedai Materials Analysis Division, Technical Department, Tokyo Institute of Technology, 4259 Nagatsuta-cho, Midori-ku, Yokohama 226-8503, Japan

${ }^{e}$ Graduate School of Engineering, Toyota Technical Institute, 2-12-1 Hisakata, Tempaku, Nagoya 468-8511, Japan

${ }^{f}$ Center of Advanced Instrumental Analysis, Kyushu University, 6-1 Kasuga-koen, Kasuga, Fukuoka 816-8580, Japan

$\dagger$ Electronic supplementary information (ESI) available. See DOI: $10.1039 / \mathrm{c} 9 \mathrm{se} 00289 \mathrm{~h}$ which uses two different semiconductor photocatalysts, is the most promising because it requires lower energy photons and allows the separation of the $\mathrm{H}_{2} / \mathrm{O}_{2}$ mixture that is generated during the water splitting reaction..$^{4-6}$ In the $\mathrm{Z}$-scheme process, the two semiconductors catalyze $\mathrm{H}_{2}$ and $\mathrm{O}_{2}$ evolution, while a redox shuttle reagent mediates electron transfer between the two materials (Scheme 1). Many semiconductors, including doped metal oxides, solid solutions and mixed anion compounds, have been assessed as visible light water-splitting photocatalysts applicable to either water reduction or oxidation in Z-scheme water splitting. ${ }^{\mathbf{4 - 1 8}}$

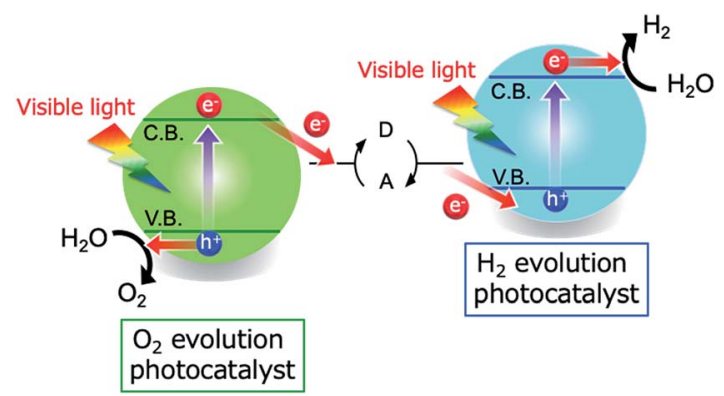

Scheme 1 A diagram showing a Z-scheme water splitting system consisting of two different semiconductors and a redox shuttle mediator 
Doping foreign elements into a metal oxide is a conventional approach to obtaining new properties that might assist in water splitting, such as visible light absorption ${ }^{\mathbf{1 2 , 1 9 , 2 0}}$ and high carrier concentrations. ${ }^{21,22}$ As an example, doping of a metal oxide with nitrogen can narrow the band gap of the oxide as a result of substitution of oxide ions with nitride ions, because the valence band potential of the oxide is shifted negatively through the contribution of the $\mathrm{N} 2 \mathrm{p}$ orbitals. ${ }^{\mathbf{1 9 , 2 0}}$ The formation of carriers due to foreign element doping ${ }^{21,22}$ or defect formation ${ }^{23}$ in a metal oxide also improves the photocatalytic activity of the oxide, especially with regard to the $\mathrm{H}_{2}$ or $\mathrm{O}_{2}$ evolution half reactions. For these reasons, carefully designed metal oxide photocatalysts based on doping have been shown to function as efficient $\mathrm{H}_{2}$ or $\mathrm{O}_{2}$ evolution photocatalyst in Z-scheme water splitting. ${ }^{4-13,15-18}$

Our group has recently reported a highly active visible-lightresponsive photocatalyst, tantalum/nitrogen codoped rutile titanium dioxide $\left(\mathrm{TiO}_{2}: \mathrm{Ta}, \mathrm{N}\right)$, that promotes the oxidation of water to $\mathrm{O}_{2}{ }^{7,24}$ This photocatalyst can be synthesized via the thermal ammonolysis of rutile $\mathrm{TiO}_{2}$ : Ta which, in turn, is produced using a microwave-assisted solvothermal approach. A solar-to-hydrogen energy conversion efficiency (STH) of $0.021 \%$ has been obtained using $\mathrm{RuO}_{2}$-modified $\mathrm{TiO}_{2}$ :Ta,N and $\mathrm{Ru}$ loaded $\mathrm{SrTiO}_{3}: \mathrm{Rh}$ as water oxidation and reduction photocatalysts, respectively, in the presence of an $\mathrm{Fe}^{3+} / \mathrm{Fe}^{2+}$ redox shuttle mediator. Transient absorption spectroscopy has demonstrated that the codoped tantalum ions in $\mathrm{TiO}_{2}: \mathrm{Ta}, \mathrm{N}$ suppress the defect formation that is otherwise associated with nitrogen doping, thereby prolonging the lifetime of photogenerated free electrons. Therefore, pre-doping of the rutile $\mathrm{TiO}_{2}$ with $\mathrm{Ta}$ is essential to the efficient functioning of this catalyst. That is, the precursor oxide (rutile $\mathrm{TiO}_{2}$ :Ta) plays an important role in synthesizing the final $\mathrm{TiO}_{2}: \mathrm{Ta}, \mathrm{N}$ material.

Microwave-assisted hydro/solvothermal synthesis is an effective approach to the preparation of nanostructured oxide materials, including photocatalyst powders. ${ }^{25-28}$ Compared to conventional heating, in which the container is heated from the outside, microwave radiation produces a rapid increase in the internal temperature of the substrate because the microwaves are directly absorbed by solvent, with the temperature rise varying based on the dielectric dissipation factor of the solvent. This rapid heating can lead to interesting phenomena, such as increased reaction rates and selective phase formation. ${ }^{29,30}$ While microwave-assisted synthesis has been widely applied to the production of various metal oxides, ${ }^{25,27-30}$ no systematic investigation of the preparation of doped metal oxides such as $\mathrm{TiO}_{2}$ :Ta has been reported.

The photocatalytic activity of a semiconductor can be promoted by surface modification with metal/metal oxide nanoparticles, acting as so-called cocatalysts. ${ }^{2,31,32}$ These cocatalysts facilitate the separation of excited charge carriers ${ }^{2,32}$ and can also serve as redox reaction sites. ${ }^{2,32}$ The modification of semiconductor photocatalysts with cocatalysts is especially effective (and even indispensable in some cases) with regard to Z-scheme water splitting in aqueous solutions containing redox shuttle mediators. This is because the cocatalyst improves the selectivity for forward reactions while suppressing undesirable backward reactions. ${ }^{\mathbf{5 , 6 , 3 2 - 3 4}}$ As an example, Domen et al. reported that a $\mathrm{RuO}_{2}$ cocatalyst on TaON promotes both the reduction of $\mathrm{IO}_{3}{ }^{-}$and the oxidation of water. ${ }^{33}$ Abe et al. developed a $\mathrm{RuO}_{2}$ cocatalyst that is active during the selective reduction of $\mathrm{IO}_{3}{ }^{-}$ and also improves $\mathrm{O}_{2}$ evolution when used as a co-modifier for a cobalt-based water oxidation cocatalyst. ${ }^{34}$ Because the effects of loading cocatalysts on rutile $\mathrm{TiO}_{2}: \mathrm{Ta}, \mathrm{N}$ photocatalysts have not yet been investigated in detail, the activity increases provided by such cocatalysts can likely still be significantly improved.

Based on this background, the present work attempted to improve the photocatalytic water oxidation activity of rutile $\mathrm{TiO}_{2}$ :Ta,N by refining the synthesis conditions for the semiconductor itself and by optimizing the cocatalyst loading. Rutile $\mathrm{TiO}_{2}$ :Ta was synthesized by a microwave-assisted solvothermal approach under various conditions and the resulting materials were used as precursors to obtain $\mathrm{TiO}_{2}: \mathrm{Ta}, \mathrm{N}$ by thermal nitridation with dry $\mathrm{NH}_{3}$ gas. The effects of the synthesis conditions applied during the solvothermal reaction on the photocatalytic activity of the $\mathrm{TiO}_{2}$ :Ta,N during water oxidation were investigated in detail. Optimizing the preparation conditions as well as the cocatalyst was found to improve the performance of this catalyst during solar-driven Z-scheme water splitting.

\section{Experimental}

\section{Preparation of photocatalysts}

Ta-doped rutile $\mathrm{TiO}_{2}$ powders were synthesized via a microwaveassisted technique previously reported in the literature. ${ }^{7}$ In this method, a quantity of $\mathrm{Ti}(\mathrm{OiPr})_{4}$ (Kanto Chemical, $>97.0 \%, 19.8-$ $19.86 \mathrm{mmol}$ ) and an appropriate volume of $\mathrm{Ta}(\mathrm{OEt})_{5}$ (SigmaAldrich, 99.98\%, $0.14-0.2 \mathrm{mmol}$ ) were added to $n$-hexane (Kanto Chemical, $>96.0 \%, 50 \mathrm{~mL}$ ) containing $\mathrm{HCl}$ (Kanto Chemical, 35-37\%, $7 \mathrm{~mL}$ ) after which the reaction solution was placed in an autoclave and heated at a specific temperature (373-423 K) for $2 \mathrm{~h}$ using microwave radiation $(400 \mathrm{~W})$. The resulting precipitate was washed with ethanol (Kanto Chemical, $>99.5 \%$ ) and water several times, and then dried at $343 \mathrm{~K}$ in an oven. Nitridation of the $\mathrm{TiO}_{2}$ :Ta powders was performed by annealing at $773 \mathrm{~K}$ under an $\mathrm{NH}_{3}$ flow (Sumitomo Seika Chemicals, $>99.9995 \%, 10 \mathrm{~mL} \mathrm{~min}^{-1}$ ) for $30 \mathrm{~min}$ in an alumina tube connected to a mass-flow controller.

Cocatalyst-loaded samples were prepared by a previously reported impregnation method. ${ }^{33}$ In each case, the photocatalyst powder was initially dispersed in an aqueous solution of the desired metal precursor with stirring. The precursor was $\mathrm{Co}\left(\mathrm{NO}_{3}\right)_{2} \cdot 6 \mathrm{H}_{2} \mathrm{O}$ (FUJIFILM Wako Pure Chemical Corporation, $>98.0 \%$ ), $\mathrm{RuCl}_{3} \cdot n \mathrm{H}_{2} \mathrm{O}$ (Furuya Metal, $\mathrm{Ru} 41.35$ wt\%), $\mathrm{Na}_{3}$ $\mathrm{RhCl}_{6} \cdot n \mathrm{H}_{2} \mathrm{O}$ (Mitsuwa Chemicals, Rh 15.3 wt\%) or $\mathrm{Na}_{2} \mathrm{IrCl}_{6}$ $\cdot 6 \mathrm{H}_{2} \mathrm{O}$ (Kanto Chemical, $>97.0 \%$ ). This was followed by evaporation of the solvent and heating at $573 \mathrm{~K}$ for $1 \mathrm{~h}$ in air.

The $\mathrm{SrTiO}_{3}: \mathrm{Rh}$ photocatalyst was obtained by a previously reported hydrothermal method. ${ }^{\mathbf{1 5 , 3 5}}$ In a typical synthesis, $\mathrm{Sr}(\mathrm{OH})_{2} \cdot 8 \mathrm{H}_{2} \mathrm{O}$ (Kanto Chemical, $>96.0 \%, 22 \mathrm{mmol}$ ), $\mathrm{TiO}_{2}$ (JRCTIO-10, The Catalysis Society of Japan, $19.6 \mathrm{mmol}$ ) and $\mathrm{Rh}\left(\mathrm{NO}_{3}\right)_{3}$ (Kanto Chemical, $>80 \%, 0.5 \mathrm{mmol}$ ) were mixed in $50 \mathrm{~mL}$ of water, after which the mixture was transferred to 
a Teflon-lined stainless-steel autoclave and heated at $433 \mathrm{~K}$ for $42 \mathrm{~h}$. The resulting precipitate was washed with hot water and room-temperature water, then dried at $363 \mathrm{~K}$ in an oven. The hydrothermal product was subsequently mixed with an additional amount of $\mathrm{Sr}(\mathrm{OH})_{2} \cdot 8 \mathrm{H}_{2} \mathrm{O}(1.4 \mathrm{mmol})$ and heated at 1273 $\mathrm{K}$ for $10 \mathrm{~h}$ in air. The resulting material was washed with water and dried at $363 \mathrm{~K}$. Finally, the Ru cocatalyst was deposited using a photodeposition method. ${ }^{\mathbf{1 3}, 18}$ In this process, the $\mathrm{SrTiO}_{3}: \mathrm{Rh}(0.3 \mathrm{~g})$ was stirred in an aqueous methanol (Kanto Chemical) solution (100 mL, $10 \mathrm{vol} \%$ ) containing $\mathrm{RuCl}_{3}$ (3 wt $\%$ vs. $\mathrm{SrTiO}_{3}: \mathrm{Rh}$ ) for $3 \mathrm{~h}$ and then washed with water several times. The powder was collected and then dispersed in a $10 \mathrm{vol} \%$ aqueous methanol solution, followed by irradiation at $\lambda>$ $400 \mathrm{~nm}$ for $3 \mathrm{~h}$ to obtain Ru-loaded $\mathrm{SrTiO}_{3}: \mathrm{Rh}\left(\mathrm{Ru} / \mathrm{SrTiO}_{3}: \mathrm{Rh}\right)$. The $\mathrm{Ru}$ cocatalyst loading on the $\mathrm{SrTiO}_{3}: \mathrm{Rh}$ was approximately $2.2 \mathrm{wt} \%$, as determined by inductively coupled plasma-mass spectrometry (ICP-MS) analysis.

\section{Characterization of photocatalysts}

The prepared samples were studied by powder X-ray diffraction (XRD; Rigaku, MiniFlex 600; $\mathrm{Cu} \mathrm{K \alpha}$ ), UV-visible diffuse reflectance spectroscopy (DRS; JASCO, V-670), transmission electron microscopy (TEM; JEOL, JEM-2010F) and X-ray photoelectron spectroscopy (XPS; Shimadzu, ESCA-3400). The binding energies were corrected with respect to the position of the $\mathrm{C} 1 \mathrm{~s}$ peak $(285.0 \mathrm{eV})$ for each sample. The chemical compositions were determined using ICP optical emission spectroscopy (ICP-OES; Agilent Technologies, 5100 VDV ICP-OES) and ICP-MS (Agilent Technologies, 7700x). Nitrogen concentrations were assessed using an elemental micro analyzer (J-Science, JM10). The Brunauer-Emmett-Teller (BET) surface areas of the specimens were measured using a BELSORP-mini (MicrotracBEL) at liquid nitrogen temperature $(77 \mathrm{~K})$.

\section{STEM observations}

Scanning transmission electron microscopy (STEM) images were acquired using an electron microscope (Thermo Fisher Scientific, Titan cubed) equipped with spherical aberration correctors (CEOS) and an energy dispersive X-ray spectroscopy (EDS) apparatus, at an acceleration voltage of $300 \mathrm{kV}$. The convergence semiangle of the incident probe was $18 \mathrm{mrad}$, with an incident probe current of $18 \mathrm{pA}$. The detector collection semiangle was from 45.8 to $200 \mathrm{mrad}$ for high-angle annular dark-field (HAADF).

\section{Transient absorption spectroscopy}

Transient absorption spectroscopy data were acquired using laboratory-built spectrometers described previously. ${ }^{36,37}$ Briefly, $\mathrm{TiO}_{2}$ :Ta,N samples were excited by $450 \mathrm{~nm}$ laser pulses from a Nd:YAG laser (Continuum, Surelite I, 6 ns duration, $1.0 \mathrm{~mJ}, 1$ $\mathrm{Hz}$ ) and the transmittance and reflectance for each specimen were determined below and above $6000 \mathrm{~cm}^{-1}$, respectively, using mid-IR (6000-1000 $\mathrm{cm}^{-1}$; MoSi coil), near-IR (10 000$6000 \mathrm{~cm}^{-1}$; halogen lamp, $50 \mathrm{~W}$ ) and visible (25000$10000 \mathrm{~cm}^{-1}$; halogen lamp, $50 \mathrm{~W}$ ) irradiation. The probe light was dispersed by the spectrometer while the monochromatized mid-IR, near-IR and visible light was detected by an MCT detector (Kolmar), an InGaAs detector and a Si photodiode, respectively. The time resolution of this spectrometer was limited to the range of 1-2 $\mu$ s as a result of the incorporation of an AC-coupled amplifier (Stanford Research Systems, SR560) in the mid-IR and near-IR regions, and to approximately $4 \mu \mathrm{s}$, due to stray light associated with the pump pulse and/or short-lived strong emission from the sample in the visible region.

\section{Photocatalytic reactions}

Photocatalytic $\mathrm{O}_{2}$ evolution reactions were conducted at room temperature using a top-irradiation type cell that was connected to a closed gas circulation system made of glass. In each trial, a $50 \mathrm{mg}$ sample was dispersed in $140 \mathrm{~mL}$ of a $10 \mathrm{mM}$ aqueous $\mathrm{AgNO}_{3}$ solution or a $1 \mathrm{mM}$ aqueous $\mathrm{FeCl}_{3}$ (Kanto Chemical, $>99.0 \%$ ) solution $(100 \mathrm{~mL})$. In trials in which the $\mathrm{O}_{2}$ evolution reaction was conducted in the co-presence of $\mathrm{Fe}^{2+}$ ions, $\mathrm{FeCl}_{2}$ (FUJIFILM Wako Pure Chemical Corporation, 99.0-102.0\%) was also added to the reactant solution. In each trial, the reaction solution was first outgassed using a vacuum pump, after which Ar gas was introduced into the reaction system to a pressure of approximately $5 \mathrm{kPa}$, and the solution was irradiated with a $300 \mathrm{~W}$ Xe lamp (Cermax, PE300BF) operating at an output current of $20 \mathrm{~A}$. The light from the lamp was collected using a CM-1 cold mirror and then passed through an L-42 cut-off filter $(\lambda>400 \mathrm{~nm})$ prior to reaching the sample. The gases evolved during the reaction were analyzed by gas chromatography (GL Sciences, GC-3200 with a thermal conductivity detector and Ar as the carrier gas).

Z-scheme overall water splitting trials were conducted in a similar manner. Quantities of the cocatalyst-modified $\mathrm{TiO}_{2}$ :$\mathrm{Ta}, \mathrm{N}(50 \mathrm{mg})$ and $\mathrm{Ru} / \mathrm{SrTiO}_{3}: \mathrm{Rh}(25 \mathrm{mg})$ powders were dispersed in an aqueous $\mathrm{FeCl}_{3}(100 \mathrm{~mL}, \mathrm{pH} 2.4)$ or tris(2,2'-bipyridyl) cobalt(II) sulfate $\left(\left[\mathrm{Co}(\mathrm{bpy})_{3}\right]^{2+}, 0.5 \mathrm{mM}\right)$ solution $(100 \mathrm{~mL}, \mathrm{pH}$ 3.8). The cobalt complex was synthesized according to a previously reported method prior to these trials. ${ }^{16}$ The $\mathrm{pH}$ of the reaction solution was adjusted to the desired value with $\mathrm{H}_{2} \mathrm{SO}_{4}$, after which the solution was outgassed and irradiated $(\lambda>400$ $\mathrm{nm})$. In the case of experiments employing simulated sunlight, a HAL-320 solar simulator (Asahi Spectra) served as the light source.

The solar-to-hydrogen energy conversion efficiency (STH) was calculated according to the equation:

$$
\operatorname{STH}(\%)=\frac{R_{\mathrm{H}} \Delta G^{0}}{P S} \times 100
$$

where $R_{\mathrm{H}}, \Delta G^{0}, P$ and $S$ are the rate of $\mathrm{H}_{2}$ evolution $\left(\mathrm{mol} \mathrm{s}^{-1}\right)$ during Z-scheme water splitting, the standard Gibbs free energy of formation for water $\left(237 \times 10^{3} \mathrm{~J} \mathrm{~mol}^{-1}\right)$, the intensity of the simulated sunlight $\left(100 \mathrm{~mW} \mathrm{~cm}^{-2}\right)$ and the irradiation area (16 $\mathrm{cm}^{2}$ ), respectively.

\section{Results and discussion}

\section{Effects of Ta doping level}

Previous work demonstrated that doping of rutile $\mathrm{TiO}_{2}$ with $\mathrm{Ta}$ followed by nitridation at the appropriate temperature was 
necessary to obtain highly active $\mathrm{TiO}_{2}: \mathrm{Ta}, \mathrm{N},{ }^{7}$ but the optimal doping amount was not determined. For this reason, we initially performed a detailed investigation of the effects of the Ta doping amount employed during the microwave-assisted solvothermal synthesis on the physicochemical and photocatalytic properties of the $\mathrm{TiO}_{2}: \mathrm{Ta}, \mathrm{N}$. In the first such trials, the microwave heating temperature was fixed at $423 \mathrm{~K}$.

Fig. 1 shows XRD patterns for samples with different Ta doping levels, before and after nitridation. The full width at half maximum (FWHM) values for the diffraction peaks at $36^{\circ}$ are summarized in Table S1. $\dagger$ Prior to nitridation, each sample produced a single-phase diffraction pattern corresponding to that expected for rutile $\mathrm{TiO}_{2}$, with no evidence of impurities (Fig. 1a). The diffraction peaks were observed to become sharper (i.e., the FWHM decreased) after annealing under a flow of $\mathrm{NH}_{3}$ gas (Fig. 1b), indicating that the nitridation promoted crystal growth. In addition, the XRD pattern for the sample containing $1.5 \mathrm{~mol} \%$ Ta exhibited peaks associated with anatase $\mathrm{TiO}_{2}$ after ammonolysis. The positions of the diffraction peaks generated by the oxide precursors changed very little after doping, even at higher Ta doping levels. This lack of change can likely be attributed to the relatively low amount of Ta that was added and/ or to the minimal difference in the ionic radii of $\mathrm{Ta}^{5+}$ and $\mathrm{Ti}^{4+}$ in a six coordination environment. ${ }^{38}$ In addition, no noticeable change in peak positions could be identified after nitridation.

Fig. 2 presents the UV-visible DRS data for the same set of samples. Each of the oxide materials exhibited an absorption edge at approximately $405 \mathrm{~nm}$, which remained almost unchanged regardless of the Ta doping amount (Fig. 2a). In contrast, the optical properties of the semiconductors were found to change following nitridation (Fig. 2b). Specifically, an absorption band attributed to electron transitions from $\mathrm{N} 2 \mathrm{p}$ to Ti 3d orbitals $^{19,20}$ appeared in the region of $400-500 \mathrm{~nm}$ following nitridation, although the absorption band at approximately $400 \mathrm{~nm}$ (assigned to the band gap of the host $\mathrm{TiO}_{2}$ : Ta) also remained. The degree of visible light absorption also varied with respect to the amount of Ta added, although there was no clear trend in these variations.

Photocatalytic $\mathrm{O}_{2}$ evolution reactions were conducted using the as-prepared $\mathrm{TiO}_{2}: \mathrm{Ta}, \mathrm{N}$ powders, modified with $0.8 \mathrm{wt} \%$ of
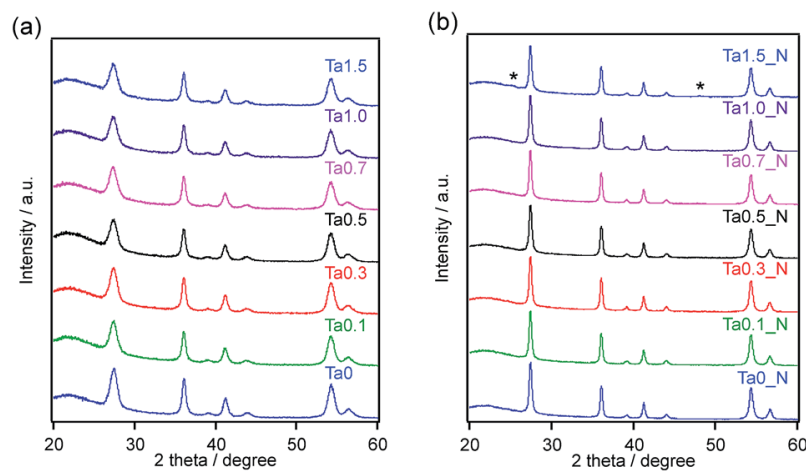

Fig. 1 XRD patterns for $\mathrm{TiO}_{2}$ :Ta prepared with different levels of $\mathrm{Ta}$ doping: (a) before and (b) after nitridation at $773 \mathrm{~K}$. Asterisks indicate diffraction peaks attributed to anatase $\mathrm{TiO}_{2}$.
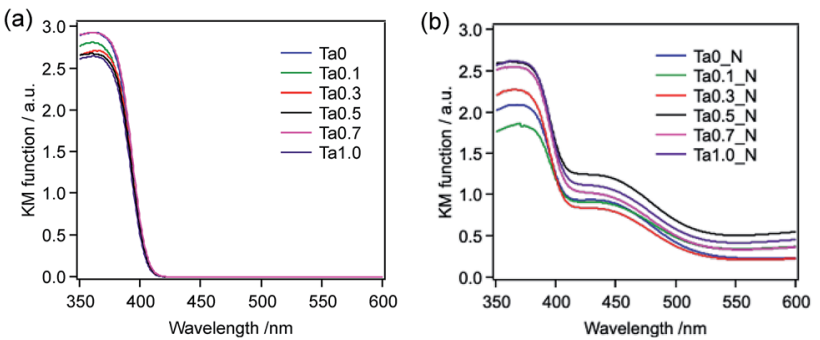

Fig. 2 UV-visible DRS spectra of $\mathrm{TiO}_{2}$ :Ta prepared with different levels of Ta doping (a) before and (b) after nitridation at $773 \mathrm{~K}$.

a $\mathrm{RuO}_{2}$ cocatalyst, in aqueous $1 \mathrm{mM} \mathrm{FeCl}$ solutions under visible light irradiation $(\lambda>400 \mathrm{~nm})$. As noted in the Introduction, the $\mathrm{RuO}_{2}$ acted as a bifunctional cocatalyst for reduction/oxidation reactions. ${ }^{31}$ The photocatalytic activity during $\mathrm{O}_{2}$ evolution was found to sharply increase with increasing Ta doping concentration up to $0.5 \mathrm{~mol} \%$, while the undoped sample did not generate $\mathrm{O}_{2}$ under the present conditions (Fig. 3). The $\mathrm{O}_{2}$ evolution rate reached a maximum at $0.5 \mathrm{~mol} \% \mathrm{Ta}$ and essentially plateaued with further increase in

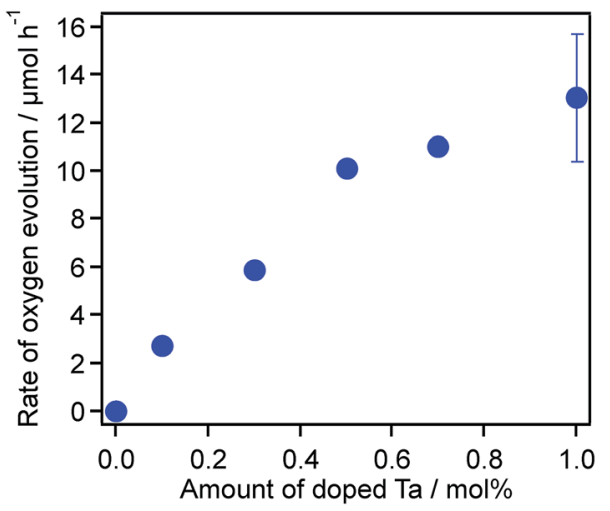

Fig. 3 Photocatalytic $\mathrm{O}_{2}$ evolution activity for $\mathrm{TiO}_{2}: \mathrm{Ta}, \mathrm{N}$ samples as a function of Ta doping level. Reaction conditions: catalyst $=50 \mathrm{mg}$ (cocatalyst $=\mathrm{RuO}_{2}$ at $0.8 \mathrm{wt} \%$ ); reactant solution $=$ aqueous $\mathrm{FeCl}_{3}$ $(1 \mathrm{mM}, 100 \mathrm{~mL})$; light source $=$ Xe lamp $(300 \mathrm{~W})$ with a cold mirror (CM-1) and a cutoff filter (L42). (a)

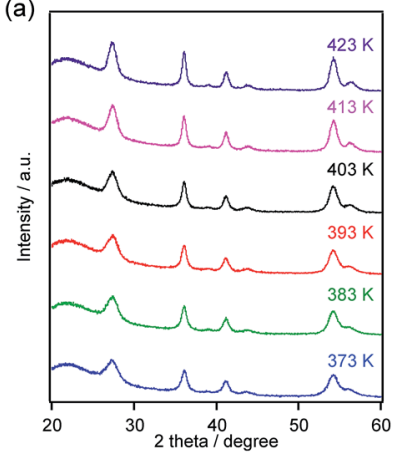

(b)

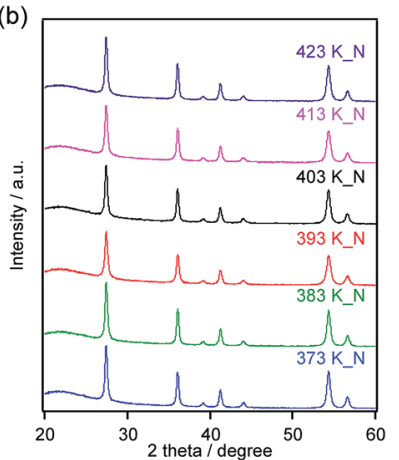

Fig. 4 XRD patterns for $\mathrm{TiO}_{2}:$ Ta specimens prepared at different temperatures (a) before and (b) after nitridation at $773 \mathrm{~K}$. 
Table 1 Physicochemical properties of $\mathrm{TiO}_{2}: \mathrm{Ta}_{1} \mathrm{~N}$ specimens prepared at different temperatures

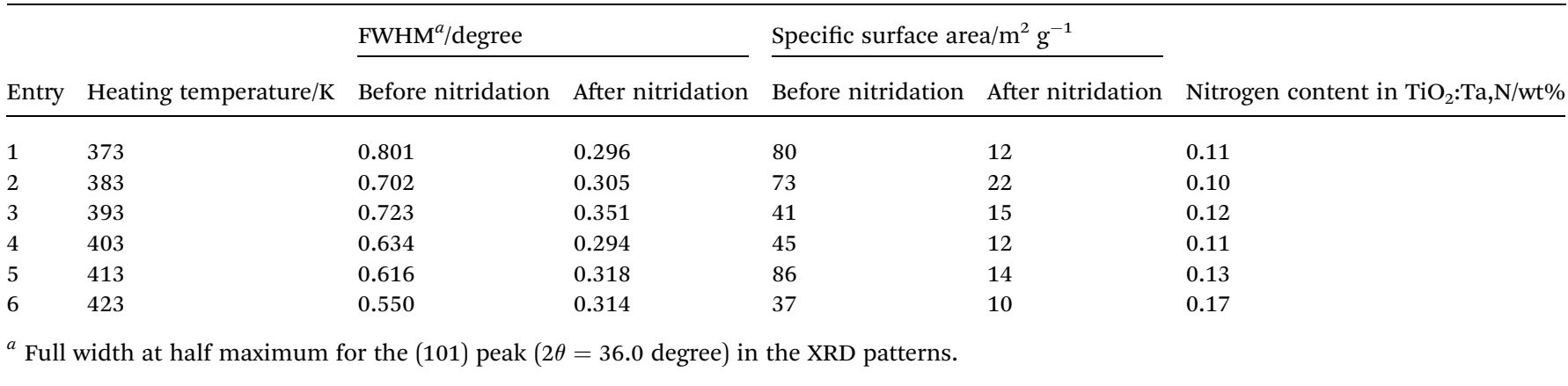

the doping level. On the basis of these results, we concluded that a Ta doping amount of $0.5 \mathrm{~mol} \%$ or more is required to permit $\mathrm{TiO}_{2}: \mathrm{Ta}, \mathrm{N}$ to exhibit high photocatalytic activity during visible-light water oxidation. In the following sections, during analysis of the microwave synthesis, the Ta doping was therefore fixed at 0.7 or $1.0 \mathrm{~mol} \%$.

\section{Effects of microwave heating temperature}

Because the microwave treatment was expected to greatly affect the $\mathrm{TiO}_{2}$ :Ta product, we investigated the effects of applying different temperatures while keeping all other synthesis parameters constant and employing a Ta concentration of 1.0 mol\%. Fig. 4a shows XRD patterns for $\mathrm{TiO}_{2}$ : Ta specimens prepared using different temperatures, while Table 1 summarizes the FWHM values for the peaks at $36^{\circ}$. All the products produced single-phase diffraction patterns attributable to rutile $\mathrm{TiO}_{2}$. The diffraction peaks became more intense and the FWHM decreased with increasing heating temperature, indicating an improvement in crystallinity.

Fig. 5 shows the particle morphology, as observed by TEM. While the morphology of the specimens heated at 383 and $423 \mathrm{~K}$ was similar (Fig. 5a and b), a portion of the latter sample evidently underwent crystal growth, forming larger particles with sizes of several hundred nanometers (Fig. 5c). This growth likely resulted from rapid, localized heating in response to the microwave radiation, and could also be related to irregular changes in the specific surface areas of the products (Table 1).

The optical properties of the oxide precursors were examined by means of UV-visible DRS. As shown in Fig. S1, $\dagger$ each specimen showed an absorption edge at approximately $405 \mathrm{~nm}$, although those samples having higher surface areas had (a)

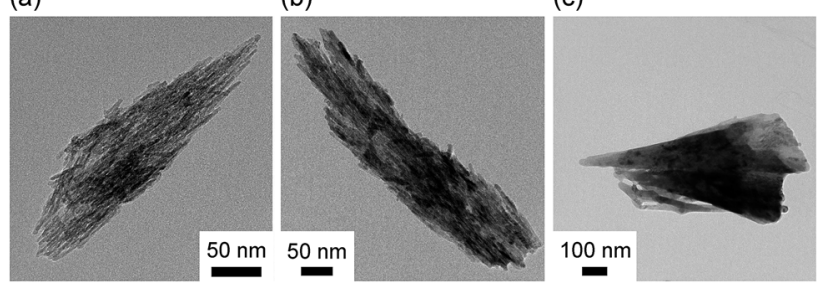

Fig. 5 TEM images of $\mathrm{TiO}_{2}: \mathrm{Ta}$ (1.0 mol\%) samples prepared at (a) 373 and ( $\mathrm{b}$ and $\mathrm{c}) 423 \mathrm{~K}$. absorption edges that were blue-shifted, most likely due to quantum size effects.

The subsequent nitridation process varied the physicochemical properties of the materials dramatically. Fig. $4 \mathrm{~b}$ shows XRD patterns for the nitrided products, using the same set of oxide materials. Each specimen produced a single-phase diffraction pattern assignable to a rutile structure after nitridation. The FWHM values for the peaks were reduced compared to those for the oxides prior to nitridation (Table 1). These results indicate that crystal growth occurred upon heating at $773 \mathrm{~K}$ under a flow of $\mathrm{NH}_{3}$, in agreement with the TEM observations (Fig. S2 $\dagger$ ). This crystal growth during nitridation was accompanied by a decrease in the specific surface area, to approximately $10-20 \mathrm{~m}^{2} \mathrm{~g}^{-1}$. Interestingly, the evident variations in the crystallinity, specific surface area and morphology between the oxide precursors disappeared completely after nitridation.

Nitridation also changed the optical properties of these materials, and Fig. 6 presents the UV-visible DRS spectra of the same series of nitrided samples. As noted above, an absorption band in the range of 400-500 $\mathrm{nm}$ appeared after nitridation. While the extent of visible light absorption varied irregularly with respect to the microwave heating temperature, the sample processed at $373 \mathrm{~K}$ showed significantly less absorption in the visible region of the spectrum. The nitrogen content was measured by elemental analysis of the same set of nitrided samples, and found to be in the range of 0.1-0.2 wt\% (Table 1).

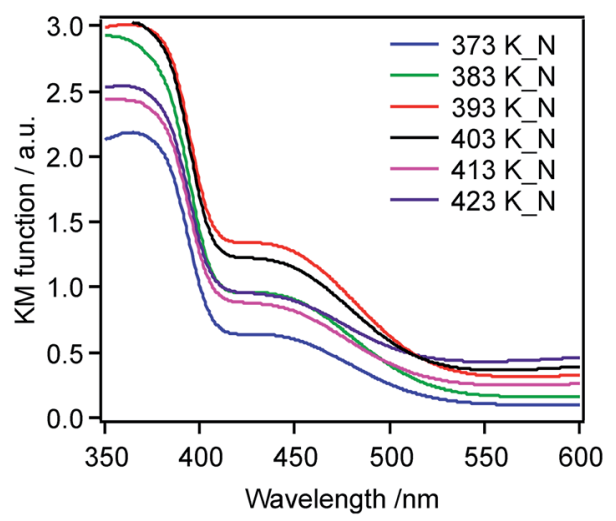

Fig. 6 UV-visible DRS spectra for $\mathrm{TiO}_{2}: \mathrm{Ta}, \mathrm{N}$ specimens made from oxide precursors $\left(\mathrm{TiO}_{2}: \mathrm{Ta}\right)$ prepared at different temperatures. 

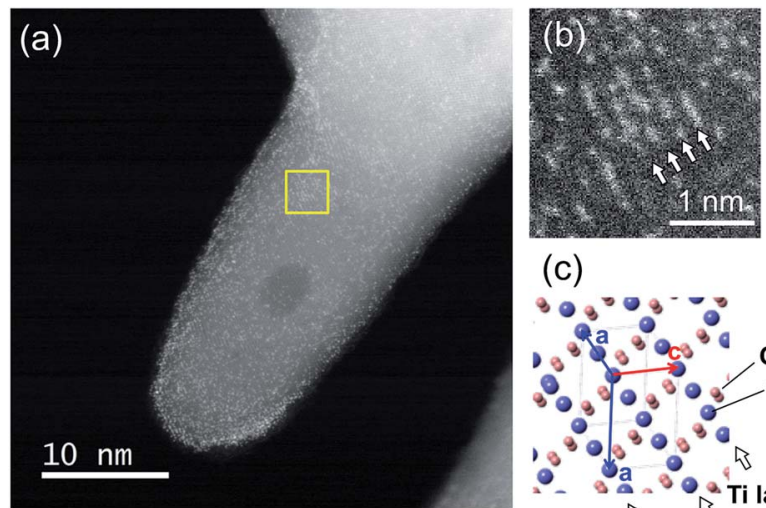

(c)
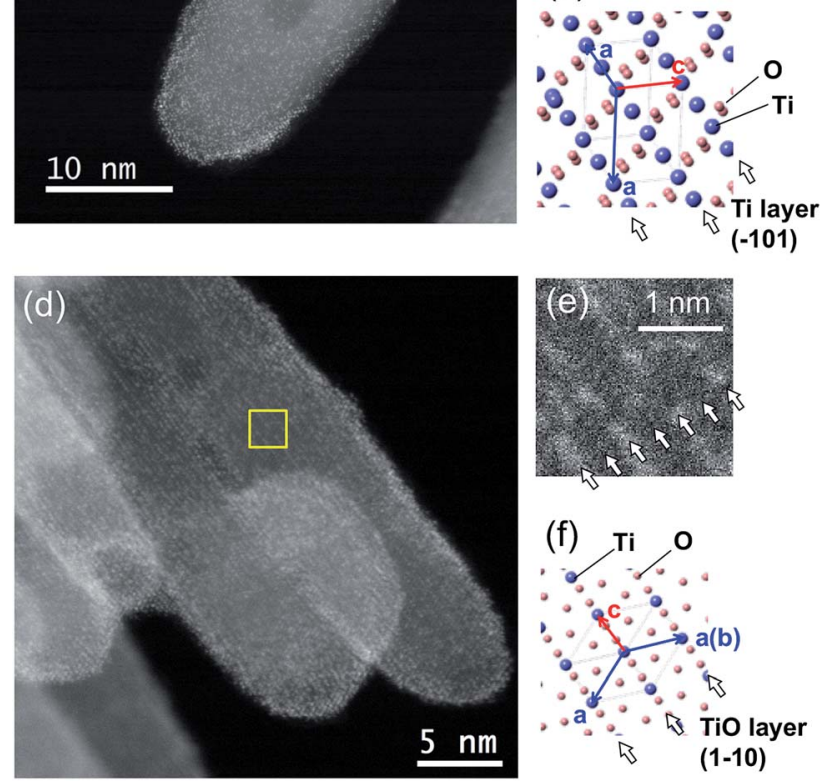

Fig. 7 HAADF-STEM images of $\mathrm{TiO}_{2}: \mathrm{Ta}, \mathrm{N}$ powder (Ta $0.7 \mathrm{~mol} \%$ ). (a and $d$ ) HAADF-STEM images and ( $b$ and e) enlarged views of the regions indicated by the yellow squares in ( $a$ and d), respectively. (c and f) Crystal structure models of $\mathrm{TiO}_{2}$ from the [121] and [111] directions.

A detailed investigation of the physicochemical state of the Ta dopants was performed so as to ascertain the occupation sites, the actual amounts and the oxidation states. Fig. 7 shows HAADF-STEM images of a $\mathrm{TiO}_{2}$ :Ta,N powder with a nominal Ta concentration of $0.7 \mathrm{~mol} \%$. The brighter spots in these images correspond to Ta ions because the signal intensity in HAADF

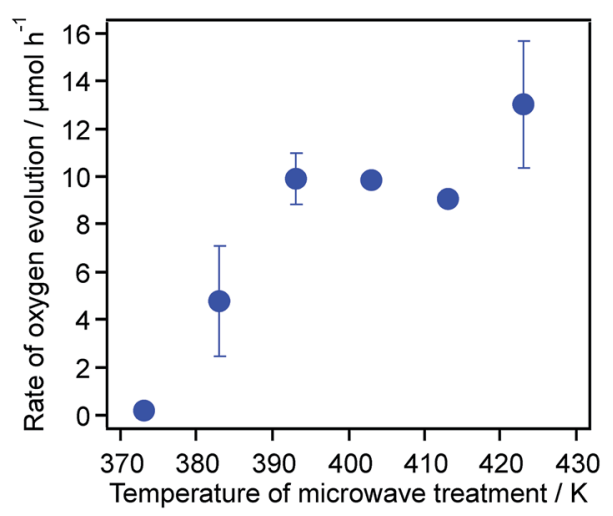

Fig. 8 Photocatalytic $\mathrm{O}_{2}$ evolution activity for $\mathrm{TiO}_{2}: \mathrm{Ta}, \mathrm{N}$ samples as a function of the temperature used to prepare the precursor. Reaction conditions: catalyst $=50 \mathrm{mg}$ (cocatalyst $=\mathrm{RuO}_{2}$ at $0.8 \mathrm{wt} \%$ ); reactant solution = aqueous $\mathrm{FeCl}_{3}(1 \mathrm{mM}, 100 \mathrm{~mL})$; light source $=$ Xe lamp (300 W) with a cold mirror (CM-1) and a cutoff filter (L42). imaging is approximately proportional to $Z^{2}$ (where $Z$ represents the atomic number). ${ }^{39}$ Here, the Ta sites are seen to be located in $\operatorname{Ti}\{101\}$ and $\operatorname{TiO}\{110\}$ layers. These sites are uniformly distributed throughout the $\mathrm{TiO}_{2}: \mathrm{Ta}, \mathrm{N}$ particles. The concentration of Ta was determined using EDS and ICP-OES. The Ta atom concentrations determined by these techniques were 0.6 and $0.9 \mathrm{~mol} \%$ (vs. Ti), respectively, both of which are close to the nominal value $(0.7 \mathrm{~mol} \%)$.

The surface oxidation state of the Ta atoms was assessed using XPS, and Fig. S3† presents the Ta $4 \mathrm{f}$ XPS spectrum of $\mathrm{TiO}_{2}$ :Ta,N (Ta: $0.7 \mathrm{~mol} \%$ ) powder. Two peaks are evident, at 28.1 and $26.3 \mathrm{eV}$, which can be assigned to $\mathrm{Ta} 4 \mathrm{f}_{5 / 2}$ and $4 \mathrm{f}_{7 / 2}$ orbitals in the $\mathrm{Ta}_{2} \mathrm{O}_{5}{ }^{40}$ It is known that the position of the Ta $4 \mathrm{f}$ photoelectron signal is sensitive to the local environment around Ta atoms, ${ }^{41}$ and these results show that the Ta atoms in the $\mathrm{TiO}_{2}: \mathrm{Ta}, \mathrm{N}$ were in the $\mathrm{Ta}(\mathrm{v})$ oxidation state even after thermal ammonolysis.

Fig. 8 plots the $\mathrm{O}_{2}$ evolution rates for the $\mathrm{TiO}_{2}$ :Ta,N samples as a function of the temperature applied during the microwave synthesis of the oxide precursors. The $\mathrm{O}_{2}$ evolution rate was dramatically accelerated with increasing temperature up to 393 $\mathrm{K}$, beyond which it remained almost unchanged.

\section{Factors affecting the photocatalytic activity of $\mathrm{TiO}_{2}: \mathrm{Ta}, \mathrm{N}$}

The results for the photocatalytic reactions indicate that the activity of $\mathrm{TiO}_{2}$ :Ta,N during $\mathrm{O}_{2}$ evolution was significantly affected by the preparation parameters (i.e., the Ta doping amount and the microwave treatment temperature), as shown in Fig. 3 and 8. There were no noticeable differences in the structural and physicochemical properties among $\mathrm{TiO}_{2}: \mathrm{Ta}, \mathrm{N}$ materials with different Ta doping levels (Fig. 1 and Table S1 $\dagger$ ). In addition, the changes observed in the UV-visible DRS spectra were minimal and somewhat irregular (Fig. 2). However, in the case of photocatalytic $\mathrm{O}_{2}$ evolution reactions in aqueous $\mathrm{FeCl}_{3}$ solutions, the activity was dramatically changed with increasing amount of Ta. In prior work, transient absorption data revealed that Ta doping is necessary to obtain a highly active photocatalyst, because the Ta suppresses the formation of oxygen defects in the $\mathrm{TiO}_{2}: \mathrm{Ta}, \mathrm{N}$, thus prolonging the lifetimes of photogenerated free and/or shallowly trapped electrons. ${ }^{7}$ Considering the results of the present study, a Ta doping level of at least $0.5 \mathrm{~mol} \%$ is likely sufficient for the suppression of defects.

The temperature applied during the microwave treatment was also found to be a very important factor affecting the photocatalytic activity (Fig. 8). Changing the temperature resulted in different degrees of crystallinity in the $\mathrm{TiO}_{2}$ : Ta precursors (Fig. 4a and Table 1), such that the photocatalytic activity of the $\mathrm{TiO}_{2}$ :Ta, $\mathrm{N}$ during $\mathrm{O}_{2}$ evolution was enhanced with increasing temperature. While the activity of these materials did not exhibit an obvious correlation with visible light absorption (Fig. 6) or surface area (Table 1), the $\mathrm{O}_{2}$ evolution rate was found to increase as the FWHM of the XRD peaks for the oxide precursors decreased (Table 1). That is, the use of more highly crystalline $\mathrm{TiO}_{2}$ :Ta tends to yield higher photocatalytic activity in the resulting $\mathrm{TiO}_{2}: \mathrm{Ta}, \mathrm{N}$. 
Transient absorption spectroscopic analyses of samples synthesized at different microwave treatment temperatures were performed to determine the lifetime of photogenerated free and/or shallowly trapped electrons. Two $\mathrm{TiO}_{2}: \mathrm{Ta}, \mathrm{N}$ samples that showed different activities (383 and $423 \mathrm{~K}$ samples) were selected. As shown in Fig. S4, $\dagger$ the lifetimes for these two specimens were almost the same, indicating that the excited carrier dynamics in both materials were similar. These equivalent excited carrier lifetimes as well as the similarities in the other physicochemical properties (e.g., crystallinity, specific surface area and light absorption) suggest that the primary factors affecting the $\mathrm{O}_{2}$ evolution activity are related to surface rather than bulk characteristics. Interestingly, when $\mathrm{Ag}^{+}$was used as an electron acceptor, the sample heated at $383 \mathrm{~K}$ showed a higher rate of $\mathrm{O}_{2}$ evolution $\left(35.1 \mu \mathrm{mol} \mathrm{h}^{-1}\right)$ than the $423 \mathrm{~K}$ sample $\left(21.0 \mu \mathrm{mol} \mathrm{h}^{-1}\right)$, as shown in Fig. S5, $\dagger$ which was opposite to the results obtained using $\mathrm{Fe}^{3+}$ as the electron acceptor (Fig. 8; $383 \mathrm{~K}, 4.8 \mu \mathrm{mol} \mathrm{h}^{-1}$ and $423 \mathrm{~K}, 13.2 \mu \mathrm{mol}$ $\left.\mathrm{h}^{-1}\right) .^{42}$ The reduction of $\mathrm{Ag}^{+}$to $\mathrm{Ag}$ is irreversible, while the $\mathrm{Fe}^{3+}$ to $\mathrm{Fe}^{2+}$ reduction is reversible, meaning that there is no competing reductant in a reactant solution containing aqueous $\mathrm{AgNO}_{3}$. In addition, $\mathrm{Fe}^{2+}$ can be photo-oxidized to $\mathrm{Fe}^{3+}$, thereby reducing the rate of the forward water oxidation reaction. We therefore propose that the higher activity for the $423 \mathrm{~K}$ sample during $\mathrm{O}_{2}$ evolution from aqueous $\mathrm{FeCl}_{3}$ is attributable to suppression of the reverse reaction (i.e., the oxidation of $\mathrm{Fe}^{2+}$ to $\mathrm{Fe}^{3+}$ ) and/or enhancement of the reduction of $\mathrm{Fe}^{3+}$.

On the basis of these results, we concluded that the appropriate choice of the oxide precursor for the $\mathrm{TiO}_{2}: \mathrm{Ta}, \mathrm{N}$ is very important for obtaining a highly active $\mathrm{TiO}_{2}: \mathrm{Ta}, \mathrm{N}$ photocatalyst. The critical factors are the Ta doping level (which should be greater than $0.5 \mathrm{~mol} \%$ ) and high crystallinity, which can be obtained by heating at temperatures above $393 \mathrm{~K}$.

\section{Effect of cocatalyst loading on the photocatalytic activity of $\mathrm{TiO}_{2}: \mathrm{Ta}, \mathbf{N}$}

Using the optimized $\mathrm{TiO}_{2}: \mathrm{Ta}, \mathrm{N}$, we subsequently investigated the effect of cocatalyst loading on the photocatalytic water oxidation activity. Table 2 provides the $\mathrm{O}_{2}$ evolution rates for aqueous $\mathrm{FeCl}_{3}$ solutions containing $\mathrm{TiO}_{2}: \mathrm{Ta}, \mathrm{N}$ (Ta: $0.7 \mathrm{~mol} \%$ ) modified with various metal oxide cocatalysts $(0.8 \mathrm{wt} \%$ each), loaded by an impregnation method. Each of these metal oxide

Table 2 The effects of modifying $\mathrm{TiO}_{2}: \mathrm{Ta}, \mathrm{N}$ with various metal oxide cocatalysts on the rate of $\mathrm{O}_{2}$ evolution in aqueous $\mathrm{FeCl}_{3}$ solutions under visible light $(\lambda>400 \mathrm{~nm})^{a}$

\begin{tabular}{llc}
\hline Entry & Cocatalyst & Rate of $\mathrm{O}_{2}$ evolution $/ \mu \mathrm{mol} \mathrm{h}$ \\
\hline 1 & None & 0.8 \\
2 & $\mathrm{CoO}_{x}$ & 2.6 \\
3 & $\mathrm{RuO}_{2}$ & 11.0 \\
4 & $\mathrm{RhO}_{x}$ & 2.5 \\
5 & $\mathrm{IrO}_{2}$ & 14.1
\end{tabular}

${ }^{a}$ Reaction conditions: catalyst $=50 \mathrm{mg}$; reactant solution $=$ aqueous $\mathrm{FeCl}_{3}(1 \mathrm{mM}, 100 \mathrm{~mL})$; light source $=\mathrm{Xe}$ lamp $(300 \mathrm{~W})$ with a cold mirror (CM-1) and a cutoff filter (L42).
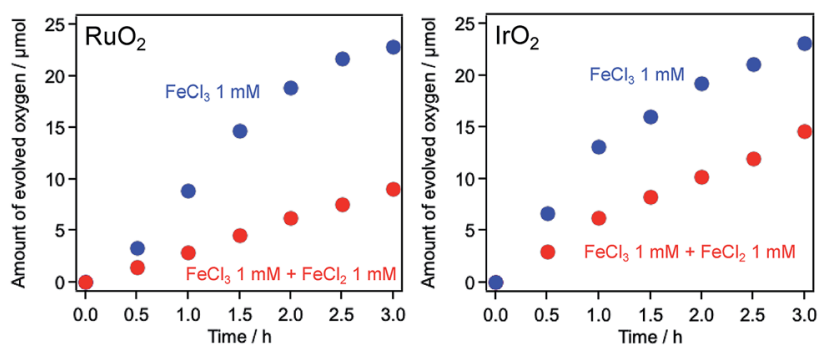

Fig. 9 Time courses for oxygen evolution over $\mathrm{RuO}_{2}$-loaded and IrO ${ }_{2}$-loaded $\mathrm{TiO}_{2}: \mathrm{Ta}_{1} \mathrm{~N}$ under visible light irradiation $(\lambda>400 \mathrm{~nm})$ in aqueous solutions containing $\mathrm{Fe}^{3+}$ and $\mathrm{Fe}^{2+}$ ions. Reaction conditions: catalyst $=50 \mathrm{mg}$ (cocatalyst as noted $=0.8 \mathrm{wt} \%$ each); reactant solution = aqueous $\mathrm{FeCl}_{3}(1 \mathrm{mM}, 100 \mathrm{~mL})$ with or without $\mathrm{FeCl}_{2}(1 \mathrm{mM})$; light source $=$ Xe lamp $(300 \mathrm{~W})$ with a cold mirror $(\mathrm{CM}-1)$ and a cutoff filter (L42).

cocatalysts facilitated the $\mathrm{O}_{2}$ evolution process as compared to the unloaded sample. The $\mathrm{IrO}_{2}$-modified sample showed the highest $\mathrm{O}_{2}$ evolution rate, with stable performance during a $15 \mathrm{~h}$ irradiation trial (Fig. S6 $\dagger$ ). $\mathrm{O}_{2}$ evolution over the $\mathrm{IrO}_{2} / \mathrm{TiO}_{2}: \mathrm{Ta}, \mathrm{N}$ was found to cease when $25 \mu \mathrm{mol}$ of $\mathrm{O}_{2}$ had been generated, which corresponds to the amount expected from the stoichiometry of a reaction involving the four-electron oxidation of water and the one-electron reduction of $\mathrm{Fe}^{3+}(100 \mu \mathrm{mol})$.

During the $\mathrm{O}_{2}$ evolution reaction from an aqueous $\mathrm{FeCl}_{3}$ solution, photo-oxidation of $\mathrm{Fe}^{2+}$ to $\mathrm{Fe}^{3+}$ can occur, competing with the forward water oxidation reaction. As discussed in the Introduction, it is important to suppress such reverse reactions, because the photo-oxidation of $\mathrm{Fe}^{2+}$ is thermodynamically more favorable than water oxidation. ${ }^{43}$ The behavior of the $\mathrm{IrO}_{2} /$ $\mathrm{TiO}_{2}$ :Ta,N photocatalyst during the $\mathrm{O}_{2}$ evolution reaction suggests that the performance of this material is relatively unaffected by the reverse reaction involving $\mathrm{Fe}^{2+}$ to $\mathrm{Fe}^{3+}$ oxidation. To further investigate the effect of $\mathrm{IrO}_{2}$ loading on photocatalytic $\mathrm{O}_{2}$ evolution from aqueous $\mathrm{FeCl}_{3}$ solutions, $\mathrm{O}_{2}$ evolution reactions were performed in the presence of $\mathrm{Fe}^{2+}$ ions. As shown in Fig. 9, the $\mathrm{O}_{2}$ evolution activity for a $\mathrm{RuO}_{2}$-loaded sample was comparable to that for an $\mathrm{IrO}_{2}$-loaded sample in an aqueous $\mathrm{FeCl}_{3}$ solution. In contrast, in an aqueous solution containing both $\mathrm{Fe}^{3+}$ and $\mathrm{Fe}^{2+}$ ions, the activity for the former material was lower than that for the latter. Iridium oxide is known to be an excellent water oxidation catalyst (or cocatalyst) with regard to the generation of $\mathrm{O}_{2},{ }^{44}$ and so loading of $\mathrm{IrO}_{2}$ on
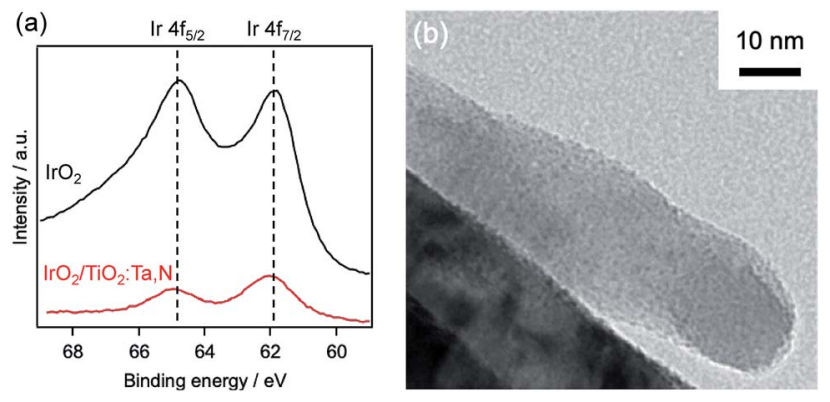

Fig. 10 Characterization of 1.0 wt\% $\mid \mathrm{rO}_{2}$-loaded $\mathrm{TiO}_{2}: \mathrm{Ta}, \mathrm{N}$. (a) Ir $4 \mathrm{f}$ XPS spectrum and (b) TEM image. 
the $\mathrm{TiO}_{2}: \mathrm{Ta}, \mathrm{N}$ likely resulted in efficient water oxidation sites even in the presence of $\mathrm{Fe}^{2+}$. This would explain the higher activity for the $\mathrm{IrO}_{2}$-loaded sample as compared to the material containing $\mathrm{RuO}_{2}$.

The physicochemical characteristics of the most active $\mathrm{IrO}_{2}-$ loaded material were further studied, and the electronic states of the $\mathrm{IrO}_{2}$ loaded on the $\mathrm{TiO}_{2}: \mathrm{Ta}, \mathrm{N}$ were investigated by XPS. Fig. 10a shows the Ir $4 \mathrm{f}$ XPS spectrum of $\mathrm{IrO}_{2}$-loaded $\mathrm{TiO}_{2}: \mathrm{Ta}, \mathrm{N}$ powder with a nominal Ta level of $0.7 \mathrm{~mol} \%$, along with reference data for pure $\mathrm{IrO}_{2}$. The spectrum exhibits two major peaks at binding energies of 64.9 and $62.0 \mathrm{eV}$, which are consistent with the $\operatorname{Ir} 4 \mathrm{f}_{5 / 2}$ and $4 \mathrm{f}_{7 / 2}$ peaks in the $\mathrm{IrO}_{2}$ reference spectrum. ${ }^{45}$ This result clearly indicates that the Ir on the $\mathrm{TiO}_{2}: \mathrm{Ta}, \mathrm{N}$ was present as $\mathrm{IrO}_{2}$.

As shown in Fig. 10b, TEM observations indicated that the $\mathrm{IrO}_{2}$ deposits were uniformly dispersed on the $\mathrm{TiO}_{2}: \mathrm{Ta}, \mathrm{N}$ surface, in the form of nanoparticles with sizes of approximately $1 \mathrm{~nm}$. These particles were readily distinguishable due to the contrast in the images resulting from the different electron densities for Ir and Ti (or Ta).

\section{Z-scheme water splitting using $\mathrm{TiO}_{2}$ :Ta, $\mathrm{N}$ as an $\mathrm{O}_{2}$ evolution photocatalyst}

$\mathrm{IrO}_{2}$-loaded $\mathrm{TiO}_{2}$ :Ta,N was subsequently applied as the water oxidation component in a Z-scheme water splitting system in combination with $\mathrm{SrTiO}_{3}: \mathrm{Rh}$ as a $\mathrm{H}_{2}$ evolution photocatalyst and in the presence of an $\mathrm{Fe}^{3+/ 2+}$ redox couple. $\mathrm{SrTiO}_{3}: \mathrm{Rh}$, which was originally developed by Kudo et al., is a promising photocatalyst for $\mathrm{H}_{2}$ evolution under visible light. ${ }^{15,16,46}$ The XRD pattern and UV-visible DRS spectrum of the $\mathrm{SrTiO}_{3}$ :Rh synthesized in this work are shown in Fig. S7. $\dagger$

Table 3 presents the rates of $\mathrm{H}_{2}$ and $\mathrm{O}_{2}$ evolution from an aqueous $\mathrm{FeCl}_{3}$ solution containing $\mathrm{IrO}_{2}$-loaded $\mathrm{TiO}_{2}$ :Ta,N (Ta: $0.7 \mathrm{wt} \%$ ) and $\mathrm{Ru}$-loaded $\mathrm{SrTiO}_{3}: \mathrm{Rh}$. These rates were strongly accelerated in the presence of a small amount of $\mathrm{FeCl}_{3}(0.2 \mathrm{mM}$, entry 2). At higher $\mathrm{FeCl}_{3}$ concentrations, the activity decreased

Table 3 Effects of iridium oxide modification and redox shuttle mediator on water splitting reaction under visible light $(\lambda>400 \mathrm{~nm})^{a}$

\begin{tabular}{|c|c|c|c|c|c|}
\hline \multirow[b]{2}{*}{ Entry } & \multirow{2}{*}{$\begin{array}{l}\text { Concentration } \\
\text { of } \mathrm{FeCl}_{3} / \mathrm{mM}\end{array}$} & \multirow{2}{*}{$\begin{array}{l}\text { Amount of loaded } \\
\mathrm{IrO}_{2} / \mathrm{wt} \%\end{array}$} & \multicolumn{2}{|c|}{$\begin{array}{l}\text { Rate of gas } \\
\text { evolution/ } \\
\mu \mathrm{mol} \mathrm{h}^{-1} \\
\end{array}$} & \multirow[b]{2}{*}{$\mathrm{H}_{2} / \mathrm{O}_{2}$ ratic } \\
\hline & & & $\mathrm{H}_{2}$ & $\mathrm{O}_{2}$ & \\
\hline 1 & 0 & 0.8 & 4.3 & 2.1 & 2.0 \\
\hline 2 & 0.2 & 0.8 & 23.7 & 12.7 & 1.9 \\
\hline 3 & 0.5 & 0.8 & 21.9 & 12.0 & 1.8 \\
\hline 4 & 1.0 & 0.8 & 18.8 & 10.2 & 1.8 \\
\hline 5 & 2.0 & 0.8 & 16.2 & 8.8 & 1.8 \\
\hline 6 & 0.2 & 0 & 8.0 & 3.8 & 2.1 \\
\hline 7 & 0.2 & 1.0 & 29.9 & 15.5 & 1.9 \\
\hline 8 & 0.2 & 1.2 & 21.5 & 10.9 & 2.0 \\
\hline 9 & 0.2 & 1.5 & 17.4 & 9.1 & 1.9 \\
\hline
\end{tabular}

${ }^{a}$ Reaction conditions: catalyst $=\mathrm{IrO}_{2} / \mathrm{TiO}_{2}: \mathrm{Ta}, \mathrm{N}, 50 \mathrm{mg}$ and $\mathrm{Ru} /$ $\mathrm{SrTiO}_{3}: \mathrm{Rh}, 25 \mathrm{mg}$; reactant solution $=$ aqueous $\mathrm{FeCl}_{3}(100 \mathrm{~mL}, \mathrm{pH}$ $2.4)$; light source $=$ Xe lamp $(300 \mathrm{~W})$ with a cold mirror $(\mathrm{CM}-1)$ and a cutoff filter (L42).

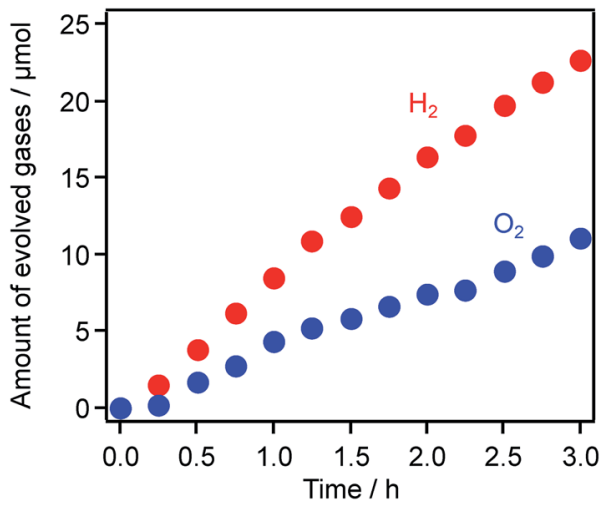

Fig. 11 Time dependence of solar-driven $\mathrm{H}_{2}$ and $\mathrm{O}_{2}$ evolution from mixtures of $1 \mathrm{rO}_{2} / \mathrm{TiO}_{2}: \mathrm{Ta}, \mathrm{N}(50 \mathrm{mg})$ and $\mathrm{Ru} / \mathrm{SrTiO}_{3}: \mathrm{Rh}(25 \mathrm{mg})$ dispersed in an aqueous $\mathrm{FeCl}_{3}$ solution $(100 \mathrm{~mL}, 0.2 \mathrm{mM})$ under simulated sunlight irradiation (AM1.5G, $100 \mathrm{~mW} \mathrm{~cm}^{-2}$ ).

gradually (entries 3-5), possibly due to the reverse reaction of $\mathrm{Fe}^{3+}$ photoreduction. Unmodified $\mathrm{TiO}_{2}: \mathrm{Ta}, \mathrm{N}$ also acted as a water oxidation photocatalyst with $\mathrm{Ru} / \mathrm{SrTiO}_{3}: \mathrm{Rh}$ in the presence of the $\mathrm{Fe}^{3+/ 2+}$ redox mediator, producing nearly stoichiometric amounts of $\mathrm{H}_{2}$ and $\mathrm{O}_{2}$ (entry 6). The water splitting activity in an aqueous $\mathrm{FeCl}_{3}$ solution was, however, improved upon loading with the $\mathrm{IrO}_{2}$ cocatalyst, by a factor of approximately 4 (entries 2, 7-9). These data again confirm the promotional effect of the $\mathrm{IrO}_{2}$ cocatalyst. In addition, the activity was increased upon increasing the concentration of the $\mathrm{IrO}_{2}$ cocatalyst to $1.0 \mathrm{wt} \%$, beyond which it began to drop. Stoichiometric water splitting into $\mathrm{H}_{2}$ and $\mathrm{O}_{2}$ under visible light irradiation was also achieved using a combination of $\mathrm{IrO}_{2} / \mathrm{TiO}_{2}: \mathrm{Ta}, \mathrm{N}$ and $\mathrm{Ru} /$ $\mathrm{SrTiO}_{3}: \mathrm{Rh}$ in aqueous solutions containing $\left[\mathrm{Co}(\mathrm{bpy})_{3}\right]^{2+}$ (Fig. S8 $\dagger$ ), which has been reported to be another effective redox mediator for Z-scheme water splitting. ${ }^{\mathbf{1 6}}$

Finally, Z-scheme water splitting was conducted under simulated sunlight (AM1.5G, $100 \mathrm{~mW} \mathrm{~cm}^{-2}$ ). As shown in Fig. 11, because $\mathrm{H}_{2}$ and $\mathrm{O}_{2}$ were generated in a nearly stoichiometric ratio, it is clear that this system exhibited solar energy conversion through overall water splitting to store chemical energy in the form of $\mathrm{H}_{2}$. The STH was calculated to be $0.039 \%$, which is 1.9 times higher than the previously reported value for a system using $\mathrm{RuO}_{2}$-loaded $\mathrm{TiO}_{2}$ :Ta,N $(0.021 \%){ }^{7}$ In addition, the STH value recorded in this work is comparable to (or a bit higher than) that achieved using a combination of $\mathrm{Ir} /$ $\mathrm{CoO}_{x} / \mathrm{Ta}_{3} \mathrm{~N}_{5}$ and $\mathrm{Ru} / \mathrm{SrTiO}_{3}: \mathrm{La} / \mathrm{Rh}(0.037 \%)$, the highest recorded STH for a Z-scheme system based on an (oxy)nitride photocatalyst as the $\mathrm{O}_{2}$ evolution component. ${ }^{47}$

\section{Conclusions}

A microwave-assisted solvothermal approach was applied to the synthesis of Ta-doped rutile $\mathrm{TiO}_{2}$, which was then subjected to thermal nitridation with dry $\mathrm{NH}_{3}$ gas to yield Ta/N-codoped rutile $\mathrm{TiO}_{2}\left(\mathrm{TiO}_{2}\right.$ :Ta,N). The use of a highly crystalline $\mathrm{TiO}_{2}$ :Ta precursor, which was obtained by microwave treatment at higher temperatures, was important for obtaining $\mathrm{TiO}_{2}: \mathrm{Ta}, \mathrm{N}$ 
that exhibited high photocatalytic activity during visible-light water oxidation. It was also found that a minimum level of Ta dopant (here, greater than $0.5 \mathrm{~mol} \%$ ) was necessary to activate the full potential of the $\mathrm{TiO}_{2}: \mathrm{Ta}, \mathrm{N}$ photocatalyst, most likely because of the associated improvement in the lifetime of photogenerated mobile electrons. While $\mathrm{TiO}_{2}$ :Ta,N showed activity during water oxidation in the presence of $\mathrm{Fe}^{3+}$ as a reversible electron acceptor, modification with an $\mathrm{IrO}_{2}$ nanoparticle cocatalyst resulted in a marked activity enhancement, by a factor of 17. The $\mathrm{IrO}_{2}$-loaded $\mathrm{TiO}_{2}: \mathrm{Ta}, \mathrm{N}$ photocatalyst could be applied to a Z-scheme water splitting system combined with $\mathrm{Ru}$ / $\mathrm{SrTiO}_{3}: \mathrm{Rh}$ in aqueous $\mathrm{FeCl}_{3}$ (or $\left[\mathrm{Co}(\mathrm{bpy})_{3}\right]^{2+}$ ) solutions under visible light. The maximum solar-to-hydrogen energy conversion efficiency reached $0.039 \%$, which was comparable to values obtained from state-of-the-art Z-scheme systems incorporating (oxy)nitride-based materials as water oxidation photocatalysts.

Although the visible light absorption capability of this doped oxide photocatalyst was inferior to that of (oxy)nitrides, we believe that carefully designed doped oxides have significant potential as photocatalysts for visible light water splitting, as clearly demonstrated in this work. Because there are a large number of metal oxides that could be used as host materials for the fabrication of doped photocatalysts, there is still much capacity for the development of more active doped photocatalysts for solar-driven water splitting. This possibility is currently under investigation in our laboratory.

\section{Author contributions}

K. M. designed the project. S. N. conducted most of the experiments and analysis, together with K. M. and M. I., J. J. M. V. and A. Y. performed the transient absorption spectroscopic analyses, D. L. conducted the TEM observations, and K. Y. and K. K. conducted the STEM observations. S. N. and K. M. wrote a draft of the manuscript. All authors discussed and provided comments on the experiments and the manuscript during preparation.

\section{Conflicts of interest}

There are no conflicts to declare.

\section{Acknowledgements}

This work was supported by a Grant-in-Aid for Scientific Research in the Innovative Area "Mixed Anion" (project numbers JP16H06438, JP16H06440, JP16H06441, JP17H05491 and JP19H04708) from JSPS. The work reported herein was also supported in part by Grants-in-Aid for Young Scientists (A) (project number JP16H06130) and for Challenging Research (Exploratory) (number JP17K19169). S. N. wishes to acknowledge the support of a JSPS Fellowship for Young Scientists (number JP18J10457).

\section{Notes and references}

1 A. Kudo and Y. Miseki, Chem. Soc. Rev., 2009, 38, 253-278.
2 K. Maeda, J. Photochem. Photobiol., C, 2011, 12, 237-268.

3 T. Hisatomi, J. Kubota and K. Domen, Chem. Soc. Rev., 2014, 43, 7520-7535.

4 K. Maeda, ACS Catal., 2013, 3, 1486-1503.

5 A. Miyoshi, S. Nishioka and K. Maeda, Chem.-Eur. J., 2018, 24, 1-17.

6 Y. Wang, H. Suzuki, J. Xie, O. Tomita, D. J. Martin, M. Higashi, D. Kong, R. Abe and J. Tang, Chem. Rev., 2018, 118, 5201-5241.

7 A. Nakada, S. Nishioka, J. J. M. Vequizo, K. Muraoka, T. Kanazawa, A. Yamakata, S. Nozawa, H. Kumagai, S. I. Adachi, O. Ishitani and K. Maeda, J. Mater. Chem. A, 2017, 5, 11710-11719.

8 A. Nakada, A. Saeki, M. Higashi, H. Kageyama and R. Abe, J. Mater. Chem. A, 2018, 6, 10909-10917.

9 K. Ogawa, A. Nakada, H. Suzuki, O. Tomita, M. Higashi, A. Saeki, H. Kageyama and R. Abe, ACS Appl. Mater. Interfaces, 2018, 11, 5642-5650.

10 S. Sun, T. Hisatomi, Q. Wang, S. Chen, G. Ma, J. Liu, S. Nandy, T. Minegishi, M. Katayama and K. Domen, ACS Catal., 2018, 8, 1690-1696.

11 A. Miyoshi, J. J. M. Vequizo, S. Nishioka, Y. Kato, M. Yamamoto, S. Yamashita, T. Yokoi, A. Iwase, S. Nozawa, A. Yamakata, T. Yoshida, K. Kimoto, A. Kudo and K. Maeda, Sustainable Energy Fuels, 2018, 2, 2025-2035.

12 A. Kudo, R. Niishiro, A. Iwase and H. Kato, Chem. Phys., 2007, 339, 104-110.

13 Y. Sasaki, A. Iwase, H. Kato and A. Kudo, J. Catal., 2008, 259, 133-137.

14 K. Maeda, M. Higashi, D. Lu, R. Abe and K. Domen, J. Am. Chem. Soc., 2010, 132, 5858-5868.

15 H. Kato, Y. Sasaki, N. Shirakura and A. Kudo, J. Mater. Chem. A, 2013, 1, 12327.

16 Y. Sasaki, H. Kato and A. Kudo, J. Am. Chem. Soc., 2013, 135, 5441-5449.

17 Q. Wang, T. Hisatomi, Q. Jia, H. Tokudome, M. Zhong, C. Wang, Z. Pan, T. Takata, M. Nakabayashi, N. Shibata, Y. Li, I. D. Sharp, A. Kudo, T. Yamada and K. Domen, Nat. Mater., 2016, 15, 611-615.

18 H. Suzuki, S. Nitta, O. Tomita, M. Higashi and R. Abe, ACS Catal., 2017, 7, 4336-4343.

19 K. Maeda and K. Domen, J. Phys. Chem. C, 2007, 111, 78517861.

20 H. Kageyama, K. Hayashi, K. Maeda, J. P. Attfield, Z. Hiroi, J. M. Rondinelli and K. R. Poeppelmeier, Nat. Commun., 2018, 9, 772 .

21 M. Higashi, Y. Yamanaka, O. Tomita and R. Abe, APL Mater., 2015, 3, 104418.

22 F. Amano, R. Tosaki, K. Sato and Y. Higuchi, J. Solid State Chem., 2018, 258, 79-85.

23 S. Nishioka, J. Hyodo, J. J. M. Vequizo, S. Yamashita, H. Kumagai, K. Kimoto, A. Yamakata, Y. Yamazaki and K. Maeda, ACS Catal., 2018, 8, 7190-7200.

24 A. Nakada, T. Uchiyama, N. Kawakami, G. Sahara, S. Nishioka, R. Kamata, H. Kumagai, O. Ishitani, Y. Uchimoto and K. Maeda, ChemPhotoChem, 2019, 3, 37-45. 
25 J. Bi, L. Wu, J. Li, Z. Li, X. Wang and X. Fu, Acta Mater., 2007, 55, 4699-4705.

26 W. Li, D. Li, W. Zhang, Y. Hu, Y. He and X. Fu, J. Phys. Chem. $C, 2010,114,2154-2159$.

27 J. H. Sun, S. Y. Dong, J. L. Feng, X. J. Yin and X. C. Zhao, J. Mol. Catal. A: Chem., 2011, 335, 145-150.

28 G. Tan, L. Zhang, H. Ren, S. Wei, J. Huang and A. Xia, ACS Appl. Mater. Interfaces, 2013, 5, 5186-5193.

29 S. Komarneni, R. Roy and Q. H. Li, Mater. Res. Bull., 1992, 27, 1393-1405.

30 K. J. Rao, B. Vaidhyanathan, M. Ganguli and P. A. Ramakrishnan, Chem. Mater., 1999, 11, 882-895.

31 K. Maeda and K. Domen, J. Phys. Chem. Lett., 2010, 1, 26552661.

32 K. Maeda and K. Domen, Bull. Chem. Soc. Jpn., 2016, 89, 627648.

33 K. Maeda, R. Abe and K. Domen, J. Phys. Chem. C, 2011, 115, 3057-3064.

34 Y. Iwase, O. Tomita, M. Higashi and R. Abe, Sustainable Energy Fuels, 2017, 1, 748-754.

35 S. Nishioka and K. Maeda, RSC Adv., 2015, 5, 100123-100128. 36 J. J. M. Vequizo, H. Matsunaga, T. Ishiku, S. Kamimura, T. Ohno and A. Yamakata, ACS Catal., 2017, 7, 2644-2651.

37 A. Yamakata, J. J. M. Vequizo and H. Matsunaga, J. Phys. Chem. C, 2015, 119, 24538-24545.
38 R. D. Shannon, Acta Crystallogr., Sect. A: Cryst. Phys., Diffr., Theor. Gen. Crystallogr., 1976, 32, 751-767.

39 S. J. Pennycook and D. E. Jesson, Ultramicroscopy, 1991, 37, 14-38.

40 S. F. Ho, S. Contarini and J. W. Rabalais, J. Phys. Chem., 1987, 91, 4779-4788.

41 W. Chun, A. Ishikawa, H. Fujisawa, T. Takata, J. N. Kondo, M. Hara, M. Kawai, Y. Matsumoto and K. Domen, J. Phys. Chem. B, 2003, 107, 1798-1803.

42 Here the $\mathrm{O}_{2}$ evolution rate from aqueous $\mathrm{AgNO}_{3}$ solution was compared by using values recorded at the initial stage of reaction, because the deposition of $\mathrm{Ag}^{0}$, as the result of reduction of $\mathrm{Ag}^{+}$, on $\mathrm{TiO}_{2}: \mathrm{Ta}, \mathrm{N}$ can hinder visible light absorption of the photocatalyst, resulting in slower rate of $\mathrm{O}_{2}$ evolution.

43 T. Ohno, D. Haga, K. Fujihara, K. Kaizaki and M. Matsumura, J. Phys. Chem. B, 1997, 5647, 6415-6419.

44 A. Harriman, I. J. Pickering, J. M. Thomas and P. A. Christensen, J. Chem. Soc., Faraday Trans. 1, 1988, 84, 2795-2806.

45 M. Rubel, R. Haasch, P. Mrozek, A. Wieckowski, C. De Pauli and S. Trasatti, Vacuum, 1994, 45, 423-427.

46 R. Konta, T. Ishii, H. Kato and A. Kudo, J. Phys. Chem. B, 2004, 108, 8992-8995.

47 Q. Wang, T. Hisatomi, S. S. K. Ma, Y. Li and K. Domen, Chem. Mater., 2014, 26, 4144-4150. 